\title{
POR UM RETORNO AO TEXTO E SEUS (DIS)SABORES: PESQUISAS SOBRE LITERATURA NO PROFLETRAS ${ }^{1}$
}

\section{FOR A RETURN TO THE TEXT AND ITS (UN)PLESANTNESS: RESEARCH ON LITERATURE IN PROFLETRAS}

\section{Luiza Helena Oliveira da Silva ${ }^{2}$ Márcio Araújo de Melo ${ }^{3}$}

\begin{abstract}
Resumo: Este artigo discorre a respeito da formação do leitor literário no contexto escolar e os caminhos trilhados por pesquisadores, professores mestrandos pelo ProfLetras. Para isso, após uma reflexão sobre os desafios que se apresentam para o problema, analis a cinco dissertações, selecionadas aleatoriamente, entre as produções das cinco regiões do país. A abordagem panorâmica serve como provocação para a necessidade de sistematização do que se tem produzido no âmbito de um programa em rede nacional que tem como questão central responder às demandas da prática docente.
\end{abstract}

Palavras-chave: formação de leitor literário; ProfLetras; pesquisas em ensino de literatura.

Abstract: This article discusses the formation of the literarature reader in the school context and the paths traversed by researchers, professors masters by ProfLetras. For this, after a reflection on the challenges that present themselves to the problem, it analyzes five dissertations, selected at random, among the productions of the five regions of the country. The panoramic approach works as a provocation for the need to systematize what has been produced within the framework of a national network program whose central question is to respond to the demands of teaching practice.

Keywords: literature reader formation; ProfLetras; research in literature teaching.

\section{Introdução}

Até bem pouco tempo, não se podia reconhecer um grande interesse por parte dos pesquisadores da literatura quanto ao ensino. Enquanto questões como a do letramento literário consolidavam-se no campo da educação, no campo das pesquisas da área da literatura, estas

\footnotetext{
${ }^{1}$ Uma primeira versão deste trabalho foi apresentada no Congresso Internacional da ABRALIC, na Universidade Federal de Uberlândia, em julho de 2018. Na ocasião, os autores organizaram um Grupo de Trabalho para discutir as pesquisas em literatura no ProfLetras.

2 Coordenadora da Unidade do ProfLetras na Universidade Federal do Tocantins. No momento, atuando no Conselho Gestor como coordenadora adjunta. E-mail: luiza.to@uft.edu.br

${ }^{3}$ Coordenador do Programa de Pós-graduação em Letras: Ensino de Língua e Literatura, da Universidade Federal do Tocantins (PPGL/UFT) e docente do ProfLetras/UFT. Membro do GT de Literatura e Ensino na ANPOLL. Email: marciodemelo33@gmail.com
} 
pareciam ser compreendidas como um problema menor, de segunda ordem, como objeto menos nobre para os interesses da área. Ao mesmo tempo, a literatura ia perdendo paulatinamente espaços na escola, lócus privilegiado para a formação de leitores, sobretudo das classes populares, deixando de constituir-se como componente curricular e tornando-se conteúdo de ensino de língua portuguesa, a ser abordado de modo interdisciplinar nas aulas de língua portuguesa (MELO e SILVA, 2011). A precariedade com que foi traduzida nos Parâmetros Curriculares Nacionais de Língua Portuguesa do Ensino Fundamental e Médio (BRASIL, 1998; 1999) fez com que houvesse uma reação teórica que resultou nas Orientações Curriculares Nacionais do Ensino Médio (BRASIL, 2006), documento em que a estética de recepção comparece como principal orientação para o tratamento do texto literário na escola. A despeito da maior densidade no tratamento das especificidades da literatura no contexto escolar, esse segundo documento parece ter tido menor alcance em suas traduções na prática na medida em que vemos o texto literário ser cada vez mais absorvido pela perspectiva hegemônica dos estudos dos gêneros, em conformidade com um modo de apropriação das ideias de Bakhtin (2000). Sob essa perspectiva, mesmo quando se faz presente enquanto materialidade discursiva na sala de aula, o texto literário passa a ser tratado como exemplar de um gênero $\mathrm{X}$, a ser reproduzido imediatamente pelas produções dos alunos, sob um viés de um ensino mais pragmático e utilitário que resulta que seja mobilizado pela urgência da apreensão de seus aspectos formais ou ainda para subsidiar atividades de análise linguística. Essa orientação segue ainda reforçada por questões de avaliações externas como ENEM ou SAEB, o que faz com que ler na escola tenha como objetivo primeiro e último apreender as constituições genéricas.

Nesse sentido, não se sabe como se faz o tratamento da leitura de Quarto de despejo: diário de uma favelada, de Carolina Maria de Jesus, numa sequência didática aplicada a uma turma de adolescentes, mas sabemos que os alunos tiveram como resultado final a produção de seus respectivos diários e é essa produção que interessa como objeto de análise ao pesquisador que a empreendeu como projeto de intervenção (DUARTE, 2016). Contos comparecem em uma outra proposta didática, mas também ali, numa nova sequência embasada nos estudos dos gêneros, o que interessou ao professor pesquisador foi a produção de novos contos (MENDONÇA e NEGRÃO, 2017) e, embora muitas vezes assumindo no texto a perspectiva sociointeracionista de leitura, as atividades de produção de sentido ficam obscurecidas pela redução das questões que guiaram a apropriação do texto, centrando-se nas condições de produção mais imediatas (quem, quando, onde etc.). 
No ProfLetras, Programa de Mestrado em Letras em Rede Nacional, a presença da literatura é tímida, contando com apenas uma disciplina no núcleo obrigatório e duas eletivas, por outro lado a linguística possui quatorze disciplinas entre obrigatórias e eletivas. Essa composição da matriz curricular faz com que também tenhamos predominantemente na composição dos colegiados das 49 unidades um número maior de professores pesquisadores da linguística em detrimento do quantitativo de professores que pesquisam literatura ${ }^{4}$. Como decorrência dessa configuração, temos, também, um número menor de pesquisas sobre a temática do ensino de literatura ou ainda a formação do leitor literário sendo produzidas no âmbito do programa.

Apesar disso, o ProfLetras colocou em pauta nacional a literatura na educação básica, contribuindo para deslocamentos dos interesses de pesquisa tradicionais. Em vez de privilegiar as análises literárias, o foco deve ser então o tratamento do literário na escola, para isso contribuindo a orientação de que todas as pesquisas realizadas no âmbito do programa tenham caráter interventivo (UFRN, 2014; 2018). Emerge daí um significativo contingente de pesquisas que certamente devem acenar para diferentes horizontes relativos ao tratamento da literatura na escola. Assim como se deu diante de pesquisadores que inicialmente se concentravam na linguística sem dedicar-se a problemas da formação de professores ou ao universo da escola e que reorientaram seus interesses de pesquisa para além da dimensão do horizonte da mera aplicação, o mesmo certamente vem se dando com pesquisadores da literatura que encontram na escola outros objetos para estudo e proposição tendo em vista os interesses da escolarização e formação de leitores literários.

Partimos do pressuposto de que a aplicação não tem um estatuto menor para o fazer científico; é antes uma necessidade, que serve para alimentar e consolidar a própria teoria e que gera, por sua vez, um campo de saberes específicos. Isso implica sair do nível da simples adaptação de conteúdos teóricos e da afastar-se da crença de sua fácil transmissibilidade, haja vista que o universo didático tem seu modo peculiar de funcionamento e impõe sua complexidade (GREIMAS e FONTANILLE, 1984). Essa complexidade se apresenta muitas vezes apagada pela redução dos projetos a uma mera questão de metodologia que supervaloriza a ação do professor, transformado em destinador que pode fazer a despeito de tudo e de todos, bastando, para isso, estar munido de um aparato teórico inicialmente não pensado em termos

\footnotetext{
${ }^{4}$ Neste momento, encontra-se em discussão a criação de uma linha em literatura no ProfLetras, atendendo a uma demanda praticamente consensual das unidades vinculadas ao ProfLetras.
} 
de sua aplicação, adaptação ou transposição para o ensino. Sob essa perspectiva, elimina-se a presença de reflexões sobre os próprios sujeitos e a escola, as condições em que se dá o ensinoaprendizagem, as coerções que agem para o sucesso e o insucesso de projetos bem intencionados e o que pode representar em ganhos efetivos a mobilização de uma teoria em proveito dos objetos de aprendizagem dos alunos.

Completando seis anos, há no ProfLetras uma produção considerável de trabalhos que ainda carecem de uma sistematização para sua apreensão. Não dispomos ainda de um repositório que abrigue todas as dissertações, muito menos que organize artigos, livros, capítulos, e-books resultantes das pesquisas do programa. Nem todas as unidades disponibilizam as dissertações para consultas online e alguns repositórios apresentam erros de acesso. Sistematizar o que se faz como pesquisa em literatura no ProfLetras será possível, portanto, apenas mediante um esforço bem mais consistente que o nosso, em caráter bastante incipiente, e que emerge como inquietação do que vimos se apresentar em trabalhos lidos por nós ainda assistematicamente, muitos deles motivados pelo convite à participação em bancas ou para apresentação de livros de trabalhos produzidos no âmbito do Programa.

Para este artigo, organizamos como corpus cinco dissertações defendidas em unidades das cinco regiões do país para uma análise de natureza qualitativa. A escolha se deu aleatoriamente, em consulta aos repositórios institucionais, tendo como critério primeiro para sua eleição que se tratassem de projetos que mobilizaram o texto literário. Ressaltamos que não se trata aqui de pensar esses trabalhos do ponto de vista de uma representação do que se faz na multiplicidade de unidades e regiões do país, mas apenas consideramos como um ponto de partida para uma primeira investigação. Buscamos observar como se organizaram as propostas de intervenção na escola a partir da literatura e que orientações teóricas subsidiaram essa dimensão da prática. A partir daí, buscamos as confluências e as dissensões. Os trabalhos selecionados foram: (D1) Do conto ao hiperconto: uma estratégia de ensino e aprendizagem em língua materna, de Verônica Diniz da Silva, defendida na UFAC, em 2018; (D2), A palavra pelas palavras: o haicai como acesso ao texto literário, de Kleber Mazione Lima Ferreira, defendida na UFMG, em 2016; (D3) De Saint-Exupéry a Limeira: uma leitura comparativa de $\mathrm{O}$ pequeno príncipe, defendida na UEM, de Pedrina Carvalho de Oliveira, em 2017; (D4) Literatura (com)tempo: intervenções a partir de crônicas em uma escola pública alagoana, de Joel Helder da Silva Morais, defendida na UFAL, em 2016; (D5) Leitura 


\section{literária e contação de histórias: perspectivas para as narrativas literárias no ensino}

fundamental, de Eleonora Alencar de Souza, defendida na UNEMAT, em 2016.

Levando em conta os limites de um artigo, faremos uma breve caracterização das dissertações para, em seguida, apontarmos para a análise propriamente dita. Ao final, esboçamos conclusões parciais sobre uma pesquisa que se encontra em andamento.

\section{A centralidade do texto, mas para fazer o quê?}

[...] quando a sociedade se queixa de que os meninos e meninas não leem, parece que se lamenta de não os ver sentados com uma obra literária nas mãos, mas o que se teme é que não dominem a língua escrita, de maneira que não tenham êxito na escola e comprometam com isso sua ascensão social. Pensa-se, pois, na função utilitária da leitura própria das classes alfabetizadas, um objetivo que inclui aspectos tão distintos como o uso do escrito ou o acesso à informação e ao conhecimento.

Teresa Colomer in: Andar entre livros

Principiamos nossa reflexão com a citação de Teresa Colomer (2007, p. 34) porque aponta para o que acreditamos ser uma questão central para docentes e pesquisadores que se ocupam da formação do leitor literário na escola. Embora a autora discorra mais de perto a respeito de aspectos que dizem respeito ao contexto europeu, sobretudo a Espanha, suas análises e contribuições trazem muitos elementos para os educadores brasileiros, dada a similaridade das situações e problemas que evoca. No Brasil, a partir dos últimos anos, observamos uma perspectiva mais pragmática e utilitária para o emprego de textos na escola, atendendo à necessidade de que os alunos dominem, sobretudo, a língua escrita, o que faz com que muitas ações didáticas comprometam a própria produção de sentidos nas aulas de leitura. Ler, sob essa orientação utilitária, é buscar apreender uma estrutura textual, a fim de que se possa, finalmente, produzir textos em conformidade com o que um dado gênero requer, o que se torna bastante difícil quando se trata de textos literários. Assim, a leitura de crônicas garante (e deve demandar) que os alunos devam saber escrever crônicas (BARBOSA, 2018)? A leitura de poemas vai necessariamente convergir para a criação poética? Considerando os interesses pragmáticos que passam a guiar a formação dos alunos, que lugar se atribui efetivamente à literatura no contexto escolar?

Tanto nos Parâmetros Curriculares Nacionais de Língua Portuguesa do Ensino Fundamental (BRASIL, 1998) quanto do Ensino Médio (BRASIL, 1999), PCN, e agora, com a Base Nacional Comum Curricular do Ensino Fundamental (BRASIL, 2017) e Médio 
(BRASIL, 2018), BNCC, defende-se que o texto tenha papel central no ensino de língua materna. Com relação ao texto literário, a BNCC insiste:

\begin{abstract}
Em relação à literatura, a leitura do texto literário, que ocupa o centro do trabalho no Ensino Fundamental, deve permanecer nuclear também no Ensino Médio. Por força de certa simplificação didática, as biografias de autores, as características de épocas, os resumos e outros gêneros artísticos substitutivos, como o cinema e as HQs, têm relegado o texto literário a um plano secundário do ensino. (BRASIL, 2018, p. 491)
\end{abstract}

A questão que se apresenta, então, é: como conferir essa centralidade de modo a garantir a formação de leitores de literatura, tendo em vista as próprias concepções de leitura subjacentes às diferentes práticas de ensino? Na mesma página, a BNCC do Ensino Médio reitera mais adiante a necessidade de "consolidação do domínio dos gêneros do discurso/gêneros textuais" (BRASIL, 2018, p. 491), confirmando a orientação assumida hoje pela maioria da produção de material didático ou mediante consensos produzidos por pesquisas que incidem sobre a prática do ensino de língua e literatura: tudo se resolve com o estudo dos gêneros. Na BNCC do primeiro segmento do Ensino Fundamental, prevê-se como objeto de conhecimento para as práticas de linguagem de leitura e escrita compartilhada e autônomas a "decodificação" e a "fluência de leitura" (BRASIL, 2017, p. 96, 110) e temos assim um quadro que define o quer ler, para que ler e o que se entende como leitura, assumidamente resumida à decodificação. A centralidade do texto nas aulas, portanto, por si só, não nos parece garantia de um trabalho que vise à formação de leitores, mas de decodificadores, pressuposto que, sob essa concepção, ler é reconhecer um sentido já dado, não uma construção que engaja o sujeito. Rejeitada há décadas pela linguística e pela literatura, a decodificação ressurge no documento, possivelmente como eco dos discursos autoritários que cerceiam a educação no contexto atual. Quem dirá o sentido verdadeiro do que deve ser então lido? Ao mesmo tempo, enunciar a leitura como decodificação apenas aclara o modo como se tem encaminhado as atividades de leitura na escola, restrita ao reconhecimento do que se acha explícito de informação, na superfície textual, mesmo quando há filiações teóricas diversas a subsidiar o trabalho: a prática registra a precariedade ou as dificuldades em transitar da teoria para a prática docente.

Numa outra direção, contra o sentido unívoco, e como resultado do que acreditamos ser uma leitura apressada das reflexões sobre a leitura subjetiva, ecoam conclusões de que qualquer leitura é possível. Rouxel e Langlade, em crítica aos efeitos do formalismo na escolarização da leitura literária apelam para o papel do sujeito leitor:

A implicação do sujeito dá sentido à prática de leitura, pois ela é, ao mesmo tempo, o signo de apropriação do texto pelo leitor e a condição necessária de um diálogo com o outro, graças à diversidade de recepções de uma mesma obra. Uma tal perspectiva 
didática - que conduz certamente a um reajustamento ideológico e uma reconfiguração prática do ensino de literatura - se contrapõe a uma tradição escolar antiga, mas ainda ativa, e a uma desconfiança crônica das teorias da literatura diante dos leitores empíricos. Mas quais poderiam ser, hoje, a razão de ser e as perspectivas de um ensino literário que ignorasse os percursos individuais e coletivos de atualização e de apropriação das obras? (ROUXEL e LANGLADE, 2013, p. 23)

Conforme esses pesquisadores franceses, é necessário levar em conta o sujeito leitor, esse leitor empírico, real, que se depara com o texto e a ele dá sentido por processos particulares - e acrescentamos também históricos e ideológicos e, portanto, sociais - de identificação, apropriação, recusa. Isso é diferente de dizer que não há nada a ensinar quanto à leitura, que não se pode negociar frente aos sentidos produzidos, ou se recusar a investigar por que se lê numa ou outra direção. Se todo sentido é possível, não está garantida, como defende Landowski, uma "ética da leitura", nem, por isso, um respeito à alteridade, nem comunicação possível pelo texto. Ler é empreender um esforço de chegar ao outro, ainda que seja para renunciar ao que ele diz.

Para frear esse delírio interpretativo, será necessário que, num certo momento, aquele
que começou a se entregar a ele renuncie à parcialidade (segundo as duas acepções do
termo) de sua leitura ou de sua escuta e se resolva, ao contrário, a reconhecer a
positividade que, justamente, preferiu ignorar: o discurso do outro enquanto
totalidade fazendo sentido. Em outros termos, seria preciso que, cessando de
privilegiar, por princípio, alguns signos artificialmente isoláveis do todo do qual
fazem parte, ele postule a possibilidade de um efeito de sentido global, ligado à
presença do outro. (LANDOWSKI, 2001, p. 34 . Grifos do autor)

Para tal, demanda-se, portanto, uma escuta sensível, habilidade que caberia ao professor ensinar, dotando-o de saberes sobre o modo de funcionamento da linguagem, dos recursos mobilizados, dos arranjos da palavra. O texto é, assim, promessa de sentido, uma totalidade com a qual o sujeito leitor interage, no exercício de atribuição de sentidos para essa alteridade ali presentificada. Lemos com nossos saberes, com nossas histórias de leituras, com nosso corpo e sensibilidade, estabelecendo distintas conexões, recortes, mediante diferentes impressões. Mas não é um vale tudo, que se traduz, ao mesmo tempo, num vale nada. Nem decodificação, construída na crença da total transparência do texto, nem a deriva total, em nome de uma acentuada perspectiva narcísica de um leitor que ignora a alteridade que se dá a (des)conhecer pela palavra.

Há muito burburinho que faz das aulas de literatura um grande acontecimento, com performances estridentes antes e depois da leitura. Mas o que é para fazer com o texto, mesmo? Abordaremos a seguir alguns dos caminhos trilhados por pesquisadores do ProfLetras. 


\section{Conto e hiperconto: a sedução pelo digital}

D1 propõe um trabalho com os gêneros conto e hiperconto, apresentando no último capítulo uma longa e detalhada sequência didática. Não se trata, porém, de uma proposta efetivamente posta em prática pela pesquisadora, mas de elaboração de uma proposição que se orienta principalmente pela crença da urgência de incorporar gêneros emergentes, no caso, o hiperconto, levando em conta o interesse dos alunos pelo universo digital e em função do caráter mais interativo previsto para o ato da leitura. No exemplo mobilizado pela pesquisadora, a sequência da narrativa e o desfecho da trama ficam a depender das seleções do leitor internauta (http://www.hiperconto.com.br/estudoemvermelho). A questão que nos colocamos é: será que, ao escolarizar usos e práticas que inicialmente seduzem os alunos internautas, esse prazer pela leitura e pela escrita se confirmaria? A escolha do hiperconto se dá apenas pelo caráter lúdico tendo em vista se tratar de uma espécie de imitação dos contos/romances policiais?

Na medida em que o ProfLetras determina que a pesquisa de caráter de intervenção seja realizada na própria turma onde leciona o docente pesquisador que deve necessariamente atuar no segundo segmento do ensino fundamental (sexto ao nono anos), uma das principais referências a nortear o trabalho são os PCN (BRASIL, 1998) que, a despeito de tematizar a especificidade da leitura do texto literário, corroborou para que fosse prioritariamente considerado na escola a partir da perspectiva dos gêneros, explicitando ainda sua função modelar para a escrita: "Para boa parte das crianças e dos jovens brasileiros, a escola é o único espaço que pode proporcionar acesso a textos escritos, textos estes que se converterão, inevitavelmente, em modelos para a produção" (BRASIL, 1998, p. 25). Devendo articular-se aos interesses da disciplina de língua portuguesa, os textos literários muitas vezes servem aos propósitos de apreensão de uma estrutura formal para as atividades de produção textual ou ainda aos interesses da análise linguística, mesmo quando se declara, como em D1, que a literatura não deve servir como pretexto para as aulas de gramática.

Essa submissão da literatura a propósitos maiores da disciplina fica expressa na própria reflexão teórica, que se introduz pelas discussões que tematizam os gêneros e sua abordagem em sequências didáticas:

Portanto, fica evidente no trabalho do professor a necessidade de levar aos educandos uma diversidade de gêneros textuais que circulam na sociedade, porque para nos comunicar linguisticamente, recorremos aos mais variados gêneros de acordo com a esfera comunicativa da qual fazemos parte e, sempre com o objetivo de melhor compreendê-los para melhor ensiná-los, através de sequências didáticas propostas por 
Dolz e Schneuwly (2011), que partem de um gênero textual, sejam eles orais ou escritos. (SILVA, 2018, p. 25)

No capítulo metodológico, posterior os capítulos teóricos que tematizam os gêneros no contexto escolar, a literatura, o letramento literário, o digital e as peculiaridades do conto e do hiperconto, a autora assume o que seriam suas motivações primeiras e o modo como se dará a abordagem do texto nas aulas:

\begin{abstract}
Inicialmente, para compreender os aspectos levantados nesta pesquisa serão realizadas leituras a respeito das questões sobre análise linguística. Faremos leituras de contos, hipercontos e romance, porque, para uma aprendizagem ser significativa, é imprescindível a prática de leitura e compreensão dos textos, pois dessa forma os alunos se apropriarão dos gêneros textuais estudados, além de entenderem quais as diferenças entre o ensino da gramática e práticas de análise linguística, principalmente como se dará o ensino de língua portuguesa, ora usando a gramática, ora usando os recursos que dão efeito de sentido ao texto como: pontuação, palavras, expressões, no caso do texto impresso e no digital, os sons, imagens, cores etc. Consultamos materiais bibliográficos que abordem a prática de análise linguística nos textos. Já com o gênero textual hiperconto, mostraremos como trabalhar as novas tecnologias da informação e da comunicação na sala de aula. (SILVA, 2018, p. 64)
\end{abstract}

Apesar da ênfase dada à análise linguística como principal estratégia para acesso ao texto e a atenção conferida à escrita como produto final, em sua proposta de intervenção, num entrecruzamento de proposições de sequências didáticas de Dolz e Schnewly (2011) e Cosson (2014), a produção de sentido na leitura ganha destaque principalmente no tratamento do conto de Mia Couto.

\title{
3 Haicai e a exploração da dimensão poética da linguagem
}

(D2) desenvolve uma proposta centrada no haicai, estabelecendo relações com a linguagem da publicitária e a poesia concreta, não apenas em função do que estas têm de concisão, mas principalmente pela aproximação quanto à exploração da dimensão estética da linguagem, somada aos recursos do visual, sem perder de vista um olhar crítico sobre textos que atendem socialmente a diferentes propósitos.

Nesse intenso contato com textos, o perfil do leitor também se modifica. Para ser leitor nessa nova configuração, é preciso intensificar práticas de leituras, ler de maneira menos programada e modular, como querem os programas e currículos que pensam em habilidades e competências.

Há que se pensar em um projeto menos moldado de leitura, que apenas vise à esquematização dos modos de ler (ler para inferir, para criticar, para relacionar), e entrelaçá-los aos modos de ler que pululam na sociedade, que invadem a vida cotidiana das pessoas, que exigem relação, conhecimento, interação, desvio, rejeição. (FERREIRA, 2016, p. 56) 
Introduz uma caracterização do gênero haicai, considerando suas variações, aspectos históricos, autores brasileiros que se dedicam ou se dedicaram a esse modo de composição poética, dando atenção especial aos elementos próprios ao plano da expressão do literário como rima, ritmo, métrica e figuras de linguagem. Ao mesmo tempo, o autor critica uma abordagem da poesia que se centra em aspectos de ordem cognitiva e que, reproduzida à exaustão nas aulas, acabariam por afastar os alunos do interesse pela leitura da poesia:

\begin{abstract}
muito mais presos a estratégias de interpretação e leitura, não conseguem deslocar-se do plano denotativo, das referências objetivas, reais, sem a devida percepção da desconstrução que se opera no registro linguístico para a tessitura estética. Daí resultaria os mais dilatados problemas relacionados à recepção dos textos literários. (FERREIRA, 2016, p. 14)
\end{abstract}

Diante disso, o professor pesquisador propõe que as atividades com leitura se organizem em diferentes etapas: uma primeira leitura, individual, sem intervenção do professor; uma leitura mediada pelo docente, com a partilha das impressões, designada como etapa de discussão; uma terceira para a percepção, que leva em conta a dimensão mais sensível do texto como objeto, constituído por uma dada estrutura, produzindo determinados efeitos de sentido pelos recursos da linguagem que explora; uma quarta e não necessariamente compreendida como última, para a apreensão, que vai considerar o grau de envolvimento dos alunos com a leitura, as articulações que estabelecem mediante seus saberes e impressões. São essas etapas de leitura e seus imbricamentos que organizarão uma oficina destinada a professores da educação básica, apresentada pormenorizadamente no último capítulo do trabalho. Num quadro síntese, organiza os elementos em diferentes níveis que poderão ser explorados nas atividades com os textos:

Quadro 1: síntese dos aspectos a serem explorados na leitura dos poemas em (D2)

\begin{tabular}{|c|c|c|c|}
\hline $\begin{array}{l}\text { EFEITO } \\
\text { ESTÉTICO }\end{array}$ & FIGURA DE LINGUAGEM & ELEMENTOS DE ANÁLISE & $\begin{array}{c}\text { FASES DE } \\
\text { DESENVOLVIMENTO DE } \\
\text { ATIVIDADE }\end{array}$ \\
\hline LEXICAL & $\begin{array}{c}\text { METÁFORAS, } \\
\text { METONÍMIAS, ANTIITESES, } \\
\text { TROCADILHOS }\end{array}$ & SELEÇÃO E COMBINAÇÃO & $\begin{array}{c}\text { LEITURA, DISCUSSÃO, } \\
\text { PERCEPÇÃO E APREENSÃO }\end{array}$ \\
\hline LÍRICO & $\begin{array}{l}\text { METÁFORAS, } \\
\text { PERSONIFICAÇÕES }\end{array}$ & $\begin{array}{l}\text { PERCEPÇÃO GERAL DO POEMA, } \\
\text { SUBJETIVIDADE }\end{array}$ & $\begin{array}{c}\text { LEITURA, DISCUSSÃO, } \\
\text { PERCEPÇÃO E APREENSÃO }\end{array}$ \\
\hline
\end{tabular}




\begin{tabular}{|c|c|c|c|}
\hline LÚDICO & $\begin{array}{l}\text { SINESTESIAS, } \\
\text { METÁFORAS, } \\
\text { METONÍMIAS }\end{array}$ & $\begin{array}{c}\text { JOGO DE SENTIDO, MÉTRICA, } \\
\text { RITMO, RIMA }\end{array}$ & $\begin{array}{l}\text { LEITURA, DISCUSSÃO, } \\
\text { PERCEPÇÃO E APREENSÃO }\end{array}$ \\
\hline VISUAL & $\begin{array}{l}\text { METALINGUAGEM, } \\
\text { PERSONIFICAÇÃOO }\end{array}$ & $\begin{array}{c}\text { ESTRUTURA, DISPOSIÇÃO DAS } \\
\text { PALAVRAS, ESPAÇOS, } \\
\text { CONFIGURAÇÕES GRÁFICAS, } \\
\text { ILUSTRAÇÃO, CORES }\end{array}$ & $\begin{array}{c}\text { LEITURA, DISCUSSÃO, } \\
\text { PERCEPÇÃO E APREENSÃO }\end{array}$ \\
\hline SONORO & $\begin{array}{l}\text { ALITERAÇÃO, } \\
\text { ASSONÂNCIA }\end{array}$ & $\begin{array}{l}\text { SONORIDADE DAS PALAVRAS, } \\
\text { RIMA, RITMO, MÉTRICA }\end{array}$ & $\begin{array}{c}\text { LEITURA, DISCUSSÃO, } \\
\text { PERCEPÇÃO E APREENSÃO }\end{array}$ \\
\hline
\end{tabular}

(FERREIRA, 2016, p. 18)

Como (D1), (D2) também não traz um resultado de intervenção, mas uma proposta que tem como produto uma minuciosa sequência de atividades que guiariam o docente no trabalho com o haicai na escola. Diferentemente de (D1), os aspectos linguísticos são explorados não a partir de um interesse primeiro de ordem gramatical, mas em função da apreensão dos recursos expressivos próprios à poesia. Nesse aspecto, há maior coerência e diálogo entre os capítulos.

\section{Literatura de cordel: hibridismo e contaminações entre erudito e popular, oralidade e escrita}

(D3) principia sua dissertação justificando a escolha do gênero cordel: o interesse demonstrado por seus alunos em suas aulas e as consequências que dele advêm para o trabalho com a literatura na escola. Suas reflexões ancoram-se inicialmente nos estudos bakhtinianos relativos aos gêneros, o que a leva a estabelecer os objetivos de seu projeto de intervenção organizado em 27 aulas, distribuídas por 7 semanas:

\footnotetext{
Acreditamos que, a partir das atividades propostas, os alunos poderão reconhecer características estilísticas, composicionais e temáticas, tanto em textos poéticos quanto em outros gêneros discursivos. Desse modo, aprenderão a valorizar a linguagem plurissignificativa e intertextual da literatura, que, ao procurar traduzir a complexidade do homem, pode humanizá-lo, conduzi-lo ao encontro com o outro e consigo mesmo. (OLIVEIRA, 2017, p. 29)
}

Após justificar a designação de "conto filosófico" para classificar O pequeno príncipe, de Saint-Exupéry, a autora discorre sobre as características do gênero, traz dados relativos à biografia do autor e ao texto do clássico francês, para, em seguida, tratar do gênero cordel e da produção escolhida, de autoria do cordelista José Limeira da Silva Júnior, que se faz presente 
também por uma entrevista. Depois de tratar com bastante profundidade a reflexão sobre a evidente dimensão intertextual/hipertextual então colocada, a pesquisadora passa a analisar o corpus, sem deixar de contrapor as ilustrações do conto e do cordel (categorias hiperestéticas), observando as coerções e possibilidades de cada gênero, as atualizações e deslocamentos produzidos por Limeira.

Finalizada a análise comparativa entre os dois textos, de Saint-Exupéry e Limeira, Oliveira apresenta então o que Cosson (2014) denomina como "sequência expandida", proposta de natureza didática para a organização de uma sequência de aulas que tomam como central um dado texto literário, geralmente do tipo narrativo e de maior extensão. Não há também, neste caso, uma aplicação efetiva em sala de aula, nem comentários acerca dos resultados obtidos com a proposta.

\footnotetext{
Esperamos que o material elaborado desperte o interesse dos alunos, tornando-os mais receptivos aos textos poéticos, à literatura popular, e que compreendam a importância da intertextualidade na interpretação de um enunciado; que outros professores de Língua Portuguesa se sintam motivados a aplicar esta "sequência" e a elaborar seu próprio material para abordagem do letramento literário, comprometendo-se com o desafio que nos está posto: a formação de leitores e, por conseguinte, de cidadãos críticos. (OLIVEIRA, 2017, p. 167)
}

Como lemos no trecho de suas considerações finais, o interesse é então uma promessa, que resultaria como efeito de um cuidadoso planejamento de atividades de leitura. Se o destinatário é inicialmente o aluno, é por extensão também o professor, que encontraria no trabalho inspiração para sua atividade docente.

\section{Crônicas literárias: em busca do pensamento crítico}

(D4) propõe uma sequência de aulas em torno da crônica, justificando sua eleição por estar previsto como gênero para a faixa etária dos alunos, por sua contemporaneidade, por sua pequena extensão que favorece a leitura em classe, pela simplicidade de sua constituição formal, por acreditar que favorece o pensamento crítico por parte do aluno. No capítulo metodológico, o autor assume a filiação da dissertação ao método dialético, segundo o qual o objeto é construído e desconstruído pelos sujeitos mediante a interação, preconizada uma relação não assimétrica entre professor e alunos, ambos concebidos como "sujeitos da aprendizagem, não havendo hierarquização, mas sim a participação mútua no processo" (MORAIS, 2016, p. 18), em nome de uma maior reciprocidade entre os sujeitos implicados. 
Seguindo os preceitos de Solé (1988), as atividades previstas para a sequência de aulas se organizam entre etapas de pré-leitura, leitura e pós-leitura. A pré-leitura compreende atividades que visam à motivação e também à produção de antecipações, que engajariam os alunos na leitura. Na pós-leitura, ocorre uma avaliação por parte do leitor quanto aos sentidos que produziu e corresponde ainda à etapa na qual se dá a discussão coletiva, com partilha dos gestos de interpretação e compreensão.

Há cuidados quanto à caracterização da escola campo: a intervenção foi realizada em uma escola do ensino fundamental situada na periferia de Maceió (AL), com problemas de infraestrutura que desfavorecem o trabalho de leitura (acústica das salas de aula). Possui uma biblioteca que se constitui apenas como local de empréstimos de livros, sem pessoal especificamente qualificado para a função, em muitos momentos mantendo-se fechada por falta de funcionário que garanta o funcionamento. A turma onde foi desenvolvido o projeto tinha alunos das classes populares, $95 \%$ deles com idade superior à faixa etária prevista para o $9^{\circ}$ ano. Depois de apresentado o que seria desenvolvido na proposta, analisa as etapas da intervenção, descrevendo a recepção e envolvimento dos alunos. A apreensão das crônicas iniciais que tematizavam a violência pode ser então observada pelas analogias que os alunos estabelecem com suas próprias experiências, num exercício comum de mobilizar uma outra figuratividade para fazer significar a primeira.

\footnotetext{
Os alunos quiseram comentar sobre casos de assaltos sofridos por eles ou por alguém próximo (familiar, amigo, vizinho). Uma aluna revelou ter sido assaltada há dois dias, e que reconhecia o assaltante, mas que não buscaria o celular por medo de represália, pois ele morava próximo a sua residência. Outros relataram conhecer algumas almas, mas que não teriam envolvimento e que já viram muitos mortos. Eles passaram a falar que, apesar da crônica ser "uma história" revelou algo "de verdade", demonstrando a percepção e a reflexão sobre a sua realidade. (MORAIS, 2016, p. 63)
}

A voz dos alunos aparece aqui em discurso indireto, mas (D4) destina um capítulo para as considerações expressas pelos adolescentes quanto aos resultados do projeto. Usando de recursos de digitalização para preservar-lhes o reconhecimento, sua presença se dá ainda pelas fotos que atualizam a sala de aula ou o auditório no qual uma das crônicas é encenada.

\section{Contação de histórias}

(D5) trata de um projeto de intervenção baseado em contação de histórias pensada como estratégia de sedução para a leitura em turma de alunos do $6^{\circ}$ ano. Na introdução, a autora 
principia com um breve histórico de seu percurso até se constituir como professora e, no primeiro capítulo traz a caracterização da escola campo de pesquisa, situada numa comunidade economicamente carente de Barra do Garças (MT). Conforme (D5), a escola tem um papel de extrema relevância do contexto social do lugar: "Diante dessa situação de carência material e até afetiva, a escola acaba sendo um lugar privilegiado dentro da comunidade, onde os alunos têm acesso a merenda, livros, recursos pedagógicos e lazer (SOUZA, 2016, p. 25).

Os textos que serviram às atividades de leitura seguiram dois critérios elementares: i. deveriam ser narrativas curtas, como contos e fábulas; ii. os autores privilegiados seriam os da região mato-grossense: "Desde o início, foi nossa intenção dar ênfase à cultura local e estadual, por meio das obras de autores que aqui escrevem, tendo por base o conhecimento transmitido oralmente" (SOUZA, 2016, p. 37). Segue-se ao capítulo teórico, que mobiliza estudos do letramento literário, leitura subjetiva e formação do leitor, aliados à concepção de leitura sociointeracionista, a descrição dos textos que serviram à contação de histórias, incluindo ilustrações, centrando-se fundamentalmente numa síntese das narrativas, sem uma efetiva análise. Não fica claro como se deu a mediação da professora após as leituras, uma vez que não parece ter sido sistematizada uma abordagem dos textos. Nesse sentido, não há como avaliar além do que revela a descrição das performances registradas no trabalho.

\section{Considerações finais, mas provisórias}

Há certamente muito a explorar no que diz respeito às contribuições dos trabalhos aqui analisados com relação aos efeitos das práticas de formação de leitor de literatura. A análise, conforme anunciamos, é breve, embora tente elencar aspectos principais para um primeiro olhar sobre o que poderiam ser tendências para a produção da área. Do ponto de vista da fundamentação teórica, há uma grande convergência entre os autores que tratam da formação do leitor de literatura. Ressalta-se ainda a aproximação com os estudos em torno da leitura trazidos pela perspectiva de leitura sociointeracionista ou dos gêneros discursivos.

Relacionamos a seguir um quadro visa sintetizar o que discutimos até o momento, a que se seguem nossas últimas considerações. 


\begin{tabular}{|c|c|c|c|c|c|c|}
\hline Região & $\begin{array}{l}\text { Trabalho } \\
\text { final }\end{array}$ & $\begin{array}{l}\text { Destinatário das } \\
\text { práticas previstas } \\
\text { ou executadas }\end{array}$ & $\begin{array}{c}\text { Efetivação } \\
\text { como } \\
\text { intervenção na } \\
\text { escola }\end{array}$ & Gêneros & $\begin{array}{l}\text { Perspectiva teórica } \\
\text { predominante }\end{array}$ & Práticas \\
\hline Norte & D1 & alunos & não & $\begin{array}{c}\text { conto; } \\
\text { hiperconto }\end{array}$ & $\begin{array}{l}\text { Estudos dos gêneros } \\
\text { discursivos }\end{array}$ & $\begin{array}{l}\text { Sequência } \\
\text { didática }\end{array}$ \\
\hline Sudeste & D2 & professores & não & $\begin{array}{l}\text { haicai; } \\
\text { poesia } \\
\text { concreta; } \\
\text { propaganda }\end{array}$ & $\begin{array}{l}\text { Letramento literário } \\
\text { e teoria literária }\end{array}$ & Oficinas \\
\hline Sul & D3 & $\begin{array}{l}\text { alunos e } \\
\text { professores }\end{array}$ & não & $\begin{array}{l}\text { cordel; } \\
\text { conto } \\
\text { filosófico }\end{array}$ & $\begin{array}{l}\text { Sociointeracionismo e } \\
\text { letramento literário }\end{array}$ & $\begin{array}{c}\text { Sequência } \\
\text { expandida de } \\
\text { leitura }\end{array}$ \\
\hline Nordeste & D4 & alunos & $\operatorname{sim}$ & crônica & marxismo & $\begin{array}{c}\text { Sequência de } \\
\text { aulas }\end{array}$ \\
\hline $\begin{array}{l}\text { Centro- } \\
\text { Oeste }\end{array}$ & D5 & alunos & sim & contos & $\begin{array}{l}\text { letramento literário e } \\
\text { linguística aplicada }\end{array}$ & $\begin{array}{l}\text { Contação de } \\
\text { histórias }\end{array}$ \\
\hline
\end{tabular}

Fonte: autores (2018)

Embora prevendo a possibilidade de outras modalidades como trabalho final, há uma evidente predileção nas unidades do ProfLetras pelo gênero dissertação, o que pode anunciar as contaminações com relação aos mestrados acadêmicos, a maior experiência dos orientadores com o gênero em questão ou ainda a crença de que traduziria melhor a cientificidade do trabalho de conclusão de um mestrado. Se a orientação primeira diz respeito ao privilégio quanto à prática (UFRN, 2014), tal nem sempre se traduz em atividades de intervenção, mas como projetos, promessas de uma prática a advir, que tomam como destinatários ora os alunos, ora os professores, os quais reproduziriam posteriormente as atividades em suas respectivas classes. A intervenção, portanto, não se efetiva em todas as situações analisadas, o que pode ser explicado pela própria exiguidade do tempo previsto para a conclusão do mestrado: em 24 meses, os mestrandos concluem 10 disciplinas (entre obrigatórias, eletivas), distribuídas por 03 semestres. Nesse curto período, docentes que não têm o benefício da licença para estudos devem cumprir todos os créditos, elaborar um projeto, desenvolver uma pesquisa, propor uma intervenção, analisar os resultados, concluir a redação e defender o trabalho final. Além disso, há que se considerar os entraves da submissão das pesquisas de intervenção trazidas pelas exigências dos Conselhos de Ética, mesmo levando em conta que podem ser encaminhados via plataforma digital (Plataforma Brasil). 
Há uma atenção especial dada a gêneros emergentes ou àqueles ainda pouco privilegiados pela abordagem mais tradicional da literatura. Observa-se ainda a opção por textos de menor extensão, que propiciam que sejam lidos integralmente no contexto da sala de aula.

A justificativa do interesse por parte do aluno quanto ao gênero adotado indica um esforço de negociação entre professores e alunos. Ensinar pressupõe então a possibilidade de negociar o que ler e como ler, tendo um pé nos objetivos da escola, outro no querer do aluno. O professor exerce assim seu poder de seduzir, de modalizar pelo querer, contando ainda para seu sucesso com a própria pregnância do objeto, a literatura, e as promessas de bem aventurança do encontro feliz: "bem-aventurado o sujeito que encontrá-lo em seu caminho" (GREIMAS, 2002, p. 51).

Há muito a ser ainda analisado, diante de um corpus composto de algumas centenas de dissertações. O que nos interessa é então pensar o que efetivamente pode contribuir para a formação de leitores de literatura as reflexões que têm lugar nesse pretensioso programa em rede nacional. Brincando com versos de Caetano Veloso, questionamos: O que quer, o que pode o ProfLetras?

\section{Referências}

BARBOSA, G. P. Aula de língua portuguesa no ensino fundamental: a prática de análise linguística em perspectiva. UFT, 2018. Dissertação (Mestrado Profissional em Letras) Universidade Federal do Tocantins. ProfLetras. Araguaína/TO, 2018, 158p.

BRASIL. Parâmetros nacionais curriculares: terceiro e quarto ciclos do ensino fundamental: língua portuguesa. Brasília: MEC/SEF, 1998.

BRASIL. Parâmetros curriculares nacionais do ensino médio. Brasília: MEC/SEMT, 1999.

BRASIL. Orientações curriculares nacionais do ensino médio. Brasília: MEC/SEMT, 2006.

BRASIL. Base nacional comum curricular: ensino médio. Brasília: MEC, 2018.

BAKHTIN, M. Estética da criação verbal. São Paulo: Martins Fontes, 2000.

COLOMER, T. Andar entre livros: a leitura literária na escola. São Paulo: Global, 2007.

COSSON, R. Círculos de leitura e letramento literário. São Paulo: Contexto, 2014.

DUARTE, Francis Paula Correa. A memória na sala: o gênero diário íntima e a (re)construção da identidade. EntreLetras, v.7, n. 2, p. 60-74, 2016.

DOLZ, J.; SCHNEUWLY, B. Gêneros orais e escritos na escola. Campinas, SP: Mercado de Letras, 2011. 
FERREIRA, K. M. L. A palavra pelas palavras: o haicai como acesso ao texto literário. UFMG, 2016. Dissertação (Mestrado Profissional em Letras) - Universidade Federal de Minas Gerais. Profletras. Belo Horizonte/MG, 2016, 135f.

GREIMAS, A. J. Da imperfeição. São Paulo: Hacker, 2002.

GREIMAS, A. J.; A. J., FONTANILLE, J. Entretien. In: FONTANILLE, J. (Org.). Langue française: sémiotique et enseignement du français. Paris: Larousse, $\mathrm{n}^{\circ}$ 61, p. 121-128, 1984.

LANDOWSKI, E. O olhar comprometido. Galaxia, n. 2, p. 17-56, 2001.

MELO, M. A. de e SILVA, A. A. Ensino a literatura: diversidade e fronteira. Polifonia (UFMT), v. 18, n. 24, p. 110-123, 2011.

MENDONÇA, S. C.; NEGRÃO, A. C. A. A escrita do gênero textual conto na $4^{\text {a }}$ etapa EJA: uma experiência com sequência didática. In: BRITO, A. R. et. al. (Orgs.) Divulgando conhecimentos de linguagem: contando experiências de ensino de língua e literatura. Acre:

NEPAN, 2017, p. 287-312.

MORAIS, J. H. S. Literatura (com)tempo: intervenções a partir de crônicas em uma escola pública alagoana. 2016. Dissertação (Mestrado Profissional em Letras) - Universidade Federal de Alagoas. Faculdade de Letras. ProfLetras. Maceió/AL, 2016, 114 f.

OLIVEIRA, P. C. De Saint-Exupéry a Limeira: uma leitura comparativa de o pequeno príncipe. UEM, 2017. Dissertação (Mestrado Profissional em Letras) - Universidade Estadual de Maringá, Centro de Ciências Humanas, Letras e Artes. ProfLetras, 2017, 182 f.

ROUXEL, A.; LANGLADE, G. Apresentação dos organizadores franceses. In: ROUXEL, A.; LANGLADE, G.; REZENDE, N. L. (Orgs.) Leitura subjetiva e ensino de literatura. São Paulo: Alameda, 2013, p. 19-24.

SILVA, V. D. Do conto ao hiperconto: uma estratégia de ensino e aprendizagem em língua materna. UFAC, 2016. Dissertação (Mestrado Profissional em Letras) - Universidade Federal do Acre. ProfLetras. Rio Branco, 2018, $105 f$.

SOLÉ, I. Estratégias de leitura. 6. ed. Porto Alegre: Artmed, 1998.

SOUZA, E. A. Leitura literária e contação de histórias: perspectivas para as narrativas literárias no ensino fundamental. 2016. Dissertação (Mestrado Profissional em Letras) Universidade do Estado de Mato Grosso. ProfLetras. Cáceres/MT, 2016, 108 f.

UNIVERSIDADE FEDERAL DO RIO GRANDE DO NORTE. Resolução $n$. 001/2014/Conselho Gestor, de 23 de abril de 2014.

UNIVERSIDADE FEDERAL DO RIO GRANDE DO NORTE. Resolução $n$. 002/2018/Conselho Gestor, de 11 de setembro de 2018. 